report, to recommend that a military lunatic asylum be provided as embraced in the design for the new military hospital at Southampton, while the letter from the DirectorGeneral, which I have printed above, (foot note, p. 271), in reply to the resolutions of this association, leads to the belief that the new military lunatic hospital will be in every way worthy of the nation.

\title{
A Letter to the Committee of Visitors of the Surrey Lunatic Asylum, by Charles Snape, Medical Superintendent. Pamphlet. Churchill.
}

Since the notice given in this Journal of the prosecution of Mr. Snape, the affair has gone through several stages. The prosecution has failed. Enquiry has been made before the visitors of the Surrey asylum, and a Jury of medical celebrities, viz., Dr. Addison, Dr. Sutherland, Dr. R. B. Todd, Dr. Babington, Dr. R. Quain, and Mr. W. Bowman. Consequent on the opinion expressed by those gentlemen, Mr. Snape has been re-instated in his office of medical superintendent. The precise terms of the verdict thus given has not transpired. Mr. Snape has embraced the opportunity of publishing that which he had previously been advised to reserve, his statement in defence. Under the extraordinary circumstances which had enveloped him, he had suffered what few are subjected to. His defence is not pure of the spirit of counter attack, which clears him less than it reflects on others. It is, however, pointed, and contains matter that is well put, that requires professional consideration, and needs to have its value more definitely determined than is to be expected in personal controversy. It is the more necessary that Mr. Snape's opinions should have full publicity, because the Press, seldom neglectful of what is exciting to the public taste, has indulged itself in the publication of attack only, while it is equal publicity that awards popular justice.

It is perhaps unfortunate for Mr. Snape, as it is unfortunate for the profession in lunacy, that the determinate enquiry did not take place in open court.

It is now needless to repeat or expose the deficiency of evidence that the patient Dolly's death was consequent on, as it was subsequent to, his undergoing the shower bath. Mr. Snape, however, adds to the information which tended to shew that his decease was irrespective of his treatment. He also 
justifies the medical use of the continuous shower bath in the treatment of mania. He says, after five years experience, "I never knew the slightest ill result, and instances can be given of entire restoration to reason, by one single fifteen or twenty minutes continuous bath." It appears, that when the bath cistern is full, the fall of water in the shower bath is rapid, and perhaps heavy; that the supply pipe of that shower bath cistern is not sufficiently large to maintain the full quantity of water to fill the cistern while the shower is in force ; that with diminished depth of water, there is less pressure, less rapidity of fall; and that in the continuous bath the depth of water in the cistern is speedily reduced to one third, by which a shower that gives a shock becomes soft and equable.

Mr. Snape considers (probably with accuracy) that continuous shower baths are much preferable to intermittent, and less distressing. He says there are cases in which discharged patients have imputed their restoration solely to the continuous baths of fifteen or twenty minutes.

$\mathrm{Mr}$. Snape is not, I believe, entitled to assume to himself that if on the 8th of April, "I had announced to the public my practice, continuous shower baths would then have been recognized as fresh resources." The profession would have had previous knowledge of the benefits attributed to the use of such baths. The professional mind was prepared to receive that truth, but not as the ' whole truth.' It is in that further knowledge that the difficulty lies. What are the particular pathological conditions or indications which guide the practitioner to the judicious use of the remedy? For the present the professional mind is not prepared to accept as fact the proposition that continuous shower baths are ordinarily suitable to patients who are maniacal and violent. Mr. Snape quotes Dr. Conolly on the obscurity of pathology of mental disorders. He quotes the opinion of Dr. Elliotson, as published in his Principles and Practice of Medicino, published, I believe, in 1839, but delivered long previously. Fair, no doubt; but what a sarcasm on medical literature, to arraign Dr. Elliotson's early writings against the opinions of his age.

The obscurity of insane pathology has been confessed at a much later period. It may appear to us that $\mathrm{Mr}$. Snape is going back to a dark age for his system of treatment, - a period of ten years distant, or it may be somewhat more! It may appear to him that fashion has made us too decidedly forgetful of what was often good and successful in the practice of that day; that the doctrine of a cool head in febrile affections still lives in the prejudices and practise of a race not yet defunct. 
The doctrine of the schools, is always to avoid suddenness and irregularity of force which will induce an irritable or spasmodic condition; and it is the gentle employment of continuous, unrelaxed exertion that will gradually orerpower the countervailing force which will never give way if you occasion shock. It does not appear that Mr. Snape administers the shower bath continuously, with benefit, in more than exceptional cases. The profession will wait for guidance before it adopts his practice. He, however, publishes frankly a statement which he has laid before the Visitors of his asylum, in correction of statements made by other officers; and courting contradiction of them if untrue.

WILLIAM LEY.

\section{THE QUARTER.}

\section{Mr. Millar and the Bucks Visitors.}

The removal of the Superintendent of the Bucks County Asylum in a manner which has excited the astonishment of our department of the profession, has been the most prominent topic of interest and remark. The letter addressed by Mr. Millar to the magistracy of Bucks, which has been placed in the hands of all the members of the Association, renders it unnecessary to enter fully into the details of this transaction. The point of view, however, taken in that pamphlet differs somewhat from that which will present itself as the one of most importance to our readers. Mr. Millar naturally desires to shew that he has committed no offence worthy of reprobation. The officers of other asylums are less interested in this question, than in the manner in which he has been ejected from his office. If even it be assumed that some serious offence or grave incompetency be imputable to him; yet if the manner of his purishment has been such that it may be employed with equal effect against the innocent and the guilty, the proceedings of the Visitors are justly liable to animadversion. That Mr. Millar was a competent superintendent is probable for several reasons : he had been the superintendent of a large pauper asylum in Middlesex, and in that appointment he had given the highest satisfaction to the Commissioners in Lunacy, under whose immediate supervision he was there placed; he had subsequently organized and for four years superintended 